\title{
Effect of inhibiting ACAT-1 expression on the growth and metastasis of Lewis lung carcinoma
}

\author{
MINGHONG BI $^{1 *}$, XUXU QIAO ${ }^{1 *}$, HAORAN ZHANG $^{1}$, HUAZHANG WU $^{2}$, ZHENYUAN GAO $^{1}$, \\ HAIRONG ZHOU ${ }^{1}$, MOHAN SHI ${ }^{1}$, YAPING WANG ${ }^{1}$, JINGRU YANG ${ }^{1}$, JIANGUO HU $^{3}$, WEICHEN LIANG ${ }^{4}$, \\ YONGHONG LIU $^{4}$, XUJIE QIAO ${ }^{4}$, SHANSHAN ZHANG ${ }^{1}$ and ZHIBIAO ZHAO ${ }^{1}$ \\ ${ }^{1}$ Department of Oncology, First Affiliated Hospital of Bengbu Medical College; \\ ${ }^{2}$ School of Life Science, Bengbu Medical College; ${ }^{3}$ Anhui Province Key Laboratory of \\ Tissue Transplantation of Bengbu Medical College; ${ }^{4}$ Graduate Department, Bengbu Medical College, \\ Bengbu, Anhui 233030, P.R. China
}

Received October 11, 2018; Accepted May 2, 2019

DOI: $10.3892 / \mathrm{ol} .2019 .10427$

\begin{abstract}
Accumulating evidence suggests that acetyl-CoA acetryltransferase 1 (ACAT-1) may mediate tumor development and metastasis. However, the specific function served by ACAT-1 in lung cancer is not well understood. Therefore, the present study initially verified that ACAT-1 was overexpressed in Lewis lung carcinoma (LLC) tissues compared with non-LLC mice and that this overexpression promoted the proliferation, invasion and metastasis of these LLC samples. Western blotting, immunofluorescence microscopy and flow cytometry allowed the present study to determine that the ACAT-1 inhibitor avasimibe significantly reduced the expression of ACAT-1 in LLC compared with LLC cells that are not treated with avasimibe $(\mathrm{P}<0.05)$. A combination of Cell Counting Kit-8 and wound healing assays demonstrated that downregulating ACAT-1 expression sufficiently inhibited the proliferation of LLC cells. Avasimibe promoted LLC cell apoptosis as assessed by a Annexin V/propidium iodide double staining assay. Furthermore, avasimibe inhibited tumor growth in vivo and improved immune responses, with tissue biopsies from LLC model mice exhibiting higher levels of ACAT-1 compared with in healthy controls. Altogether, the results of the present study reveal that avasimibe may inhibit the progression of LLC by downregulating the expression of ACAT-1, which may thus be a potential novel therapeutic target for lung cancer treatment.
\end{abstract}

Correspondence to: Professor Minghong $\mathrm{Bi}$, Department of Oncology, First Affiliated Hospital of Bengbu Medical College, 287 Changhuai Road, Bengbu, Anhui 233030, P.R. China

E-mail: bmh2003@126.com

*Contributed equally

Key words: Lewis lung carcinoma, acetyl-CoA acetyltransferase 1, Avasimibe, tumor growth, tumor metastasis

\section{Introduction}

Lung cancer remains the most common form of cancer, with the highest mortality rate globally, making it a major public health threat $(1,2)$. Surgery, chemotherapy, radiotherapy and molecular targeted therapies are currently the primary treatment options for this disease (3). Whilst early lung cancer may be treated surgically, the treatment options for advanced metastatic lung cancer are limited. Although radiotherapy and chemotherapy postpone the progression of these advanced lung cancer types, the survival rate of patients is low, and patients are often unable to tolerate the side effects of these therapies. Molecular targeted therapies are only effective in patients with lung adenocarcinoma who have specific mutations in genes including epidermal growth factor receptor (EGFR) or ALK receptor tyrosine kinase (ALK) $(4,5)$. Patients who have wild-type EGFR or ALK and non-adenovirus-associated non-small cell lung cancer lack effective targeted therapies. Thus, there remains a clear need for the identification of novel therapeutics suitable for treating patients with advanced lung cancer.

The enzyme acetyl-CoA acetyltransferase 1 (ACAT-1) is a central mediator of the cholesterol esterification pathway (6). Previous studies have identified that ACAT-1 is abnormally expressed in certain cancer types, including prostate cancer, pancreatic cancer, leukemia, glioma, breast cancer and colon cancer (7-12). However, the functions of ACAT-1 in lung cancer are not well understood. In the present study, the effects of the inhibition of ACAT-1 on Lewis lung cancer (LLC) growth and metastasis were investigated using in vitro cellular experiments and in vivo animal models. The effect of downregulation of ACAT-1 expression on proliferation, migration and apoptosis of LLC cells was observed at the cell level in vitro. The effects of ACAT-1 inhibitor avasimibe on tumor growth and metastasis in LLC mice were observed in an animal model in vivo, and the expression of ACAT-1 in Lewis lung carcinoma tissues was detected to add new content for lung cancer research and provide new strategies for clinical lung cancer treatment. 


\section{Materials and methods}

Ethics statement. The Research Ethics Committee of Bengbu Medical College (Bengbu, China) ethically approved this study.

Cell culture. The LLC cell line is a malignant murine lung cancer cell line which was obtained from the Type Culture Collection of the Chinese Academy of Sciences (Shanghai, China). LLC cells were grown in $25 \mathrm{~cm}^{3}$ cell culture vessels containing Dulbecco's modified Eagle's medium (DMEM; Hyclone; GE Healthcare Life Sciences, Logan, UT, USA), $10 \%$ foetal bovine serum (FBS; Hangzhou Sijiqing Biological Engineering Materials Co., Ltd., Hangzhou, China) and penicillin/streptomycin in standard growth conditions $\left(37^{\circ} \mathrm{C}\right)$. After culturing for approximately 3 days, cell subculture was performed when the cell density reached $\sim 80 \%$ of the bottom of the culture bottle.

Cell viability assessment. Cell proliferation was measured using a Cell Counting Kit-8 (CCK-8; Biosharp; Beijing Lanjieke Technology Co., Ltd., Hefei, China) assay, as previously described (13). Briefly, LLC cells in the logarithmic phase of growth were harvested, resuspended at $5 \times 10^{4} / \mathrm{ml}$, and $100 \mu \mathrm{l}$ cells were added to a 96 well plate $(5,000$ cells/well $)$ with five replicates per condition. Once adherence to the plates was achieved, a concentration gradient of avasimibe (Med Chem Express LLC, Monmouth Junction, NJ, USA) of $0.0,2.5,5.0,10.0$ and $20.0 \mu \mathrm{M}$ was added to the corresponding wells. Following 24, 48, 72 or $96 \mathrm{~h}$ of incubation at $37^{\circ} \mathrm{C}$, CCK-8 solution was added to each well followed by a $1-4 \mathrm{~h}$ incubation at $37^{\circ} \mathrm{C}$. The optical density at $450 \mathrm{~nm}$ was then determined via a microplate reader (BioTek Instruments, Inc., Winooski, VT, USA). Viability percentages were determined by comparing with the blank for control and treated samples.

Wound healing assay. This assay was conducted as described previously (14). Briefly, LLC cells were plated in 6-well plates ( $5 \times 10^{5}$ cells/well). Subsequent to achieving $90 \%$ confluency, a vertical scratch (width, $\sim 900 \mu \mathrm{m}$ ) was created in the monolayer using a sterile pipette tip. Plates were then washed using phosphate buffered saline (PBS) and serum-free DMEM containing either 0,5 or $10 \mu \mathrm{M}$ avasimibe was added to the appropriate wells. After $48 \mathrm{~h}$, cell migration was observed and photographed at 0 and $48 \mathrm{~h}$ after scratching. The width of the healing wound was calculated using ImageJ software (version 1.8.0; National Institutes of Health, Bethesda, MD, USA). The wound healing rate was determined based on the ratio of the change in the scratch width to the initial scratch width.

Flow cytometry. LLC cells were plated in a 6 well plate $\left(5 \times 10^{5}\right.$ cells $\left./ \mathrm{ml}\right)$ and harvested after $72 \mathrm{~h}$ treatment with 0,10 or $20 \mu \mathrm{M}$ avasimibe. Cells were then fixed at room temperature in 4\% paraformaldehyde (Sigma-Aldrich; Merck KGaA, Darmstadt, Germany) for $30 \mathrm{~min}$, prior to permeabilization using 0.1\% Triton X-100 (Sigma-Aldrich; Merck $\mathrm{KGaA}$ ) for $20 \mathrm{~min}$. The cells were then blocked in $5 \%$ goat serum (Hangzhou Sijiqing Biological Engineering Materials Co., Ltd.) and $0.3 \%$ Triton $\mathrm{X}-100$ for $30 \mathrm{~min}$ at $37^{\circ} \mathrm{C}$. Cells were incubated with anti-ACAT-1 antibody (pAb; 1:200; catalog no. \#44276; Cell Signaling Technology, Inc., Danvers, MA, USA) for $30 \mathrm{~min}$ at $37^{\circ} \mathrm{C}$ followed by fluorescein isothiocyanate (FITC)-labeled goat anti-rabbit immunoglobulin G (IgG; 1:200; catalog no. \#4412; Cell Signaling Technology, Inc.) for $30 \mathrm{~min}$ at $37^{\circ} \mathrm{C}$. The cells were washed 2-3 times with $3 \mathrm{ml}$ TPBS buffer. A Cytomics FC 500 flow cytometer (BD FACSCalibur; BD Biosciences, Franklin Lakes, NJ, USA) was then used to detect labeled cells. Mean fluorescence intensity was analyzed using FlowJo software (version 7.6; FlowJo LLC, Ashland, OR, USA).

Western blotting. LLC cells were seeded $\left(1 \times 10^{6}\right.$ cells $\left./ \mathrm{ml}\right)$ into $60 \mathrm{~mm}$ culture dishes and harvested after $72 \mathrm{~h}$ treatment with 0 or $10 \mu \mathrm{M}$ avasimibe. Subsequent to washing three times with PBS, a cell lysis buffer (PMSF:RIPA=1:100; Beyotime Institute of Biotechnology, Shanghai, China) was used to harvest the cells, and protein was quantified via a BCA assay (Beyotime Institute of Biotechnology). Samples were then separated via SDS-PAGE (10\% gel) with $30 \mu \mathrm{g}$ per lane and then transferred to a polyvinylidene fluoride membrane (Beyotime Institute of Biotechnology). A total of 5\% skim milk was used for membrane blocking for $2 \mathrm{~h}$ at room temperature, and membranes were incubated at $4^{\circ} \mathrm{C}$ with the primary antibody (rabbit anti-mouse ACAT-1 polyclonal antibody; 1:1,000; catalog no. \#44276; Cell Signaling Technology, Inc.) overnight. A horseradish peroxidase-conjugated secondary anti-rabbit IgG antibody (goat anti-rabbit IgG; 1:8,000; catalog no. BL003A; Biosharp; Beijing Lanjieke Technology Co., Ltd.) was then used for detection for $2 \mathrm{~h}$ at $37^{\circ} \mathrm{C}$. ACAT-1 was then visualized using an ECL (EMD Millipore, Billerica, MA, USA) chromogenic reaction in a dark room. Bands were quantified using ImageJ software (version 1.8.0; National Institutes of Health, Bethesda, MD, USA).

Immunofluorescence. LLC cells were seeded onto coverslips $\left(1 \times 10^{5}\right.$ cells $\left./ \mathrm{ml}\right)$. Following treatment with 0 and $10 \mu \mathrm{M}$ avasimibe for $72 \mathrm{~h}$, the coverslips were fixed using $4 \%$ paraformaldehyde and permeabilized as aforementioned, and were then blocked in 5\% goat serum and $0.3 \%$ Triton X-100 for $30 \mathrm{~min}$ at $37^{\circ} \mathrm{C}$. The coverslips were then incubated with anti-ACAT-1 antibody (pAb; 1:200; catalog no. \#44276; Cell Signaling Technology, Inc., Danvers, MA, USA) for $30 \mathrm{~min}$ at $37^{\circ} \mathrm{C}$ and then incubated with FITC-labeled goat anti-rabbit IgG (1:50; catalog no. BL003A; Biosharp; Beijing Lanjieke Technology Co., Ltd.) for $30 \mathrm{~min}$ at $37^{\circ} \mathrm{C}$. DAPI (Beyotime Institute of Biotechnology) nuclear staining was then performed while samples were in the dark for $5 \mathrm{~min}$ at room temperature. Subsequent to rinsing with PBS, the coverslips were fixed on glass slides using 1:1 glycerol:water for $5 \mathrm{~min}$ at room temperature. Confocal microscopy (magnification, $\mathrm{x} 600$; FV-1200MPE SHARE; Olympus Corporation, Tokyo, Japan) was used for imaging, and Image J software (version 1.8.0; National Institutes of Health, Bethesda, MD, USA) was used for quantitative analyses.

Apoptosis detection. Apoptosis was detected using an Apoptosis Detection kit (Nanjing KeyGen Biotech Co., Ltd., Nanjing, China) according to the manufacturer's protocol. Subsequent to LLC cell treatment with avasimibe ( 0 and $10 \mu \mathrm{M})$ for $72 \mathrm{~h}$, 
the cells were digested with EDTA-free trypsin and resuspended in $500 \mu \mathrm{l}$ binding buffer. Samples were then stained with 1:100 annexin $\mathrm{V}$ and propidium iodide for $10 \mathrm{~min}$ at $4^{\circ} \mathrm{C}$ in the dark, and cells were detected using flow cytometry as described above. The rate of apoptosis was analyzed using FlowJo software (version 7.6; FlowJo LCC

In vivo mouse model experiments. A total of 24 male C57BL/6 mice (age range, 8-10 weeks; weight, 18-22 g) were obtained from the Experimental Animal Center of Bengbu Medical College (Bengbu, China). The mice were housed in a pathogen-free central animal facility (temperature, $20 \sim 26^{\circ} \mathrm{C}$; relative humidity, 40 70\%; light-dark alternate time, $12 / 12 \mathrm{~h}$; food and water were disinfected and sterilized, the mice had continuous access to the food and water) at the Bengbu Medical College. The animal experiments were performed based on the recommendations provided in the National Institutes of Health Laboratory Animal Care and Use Guidelines (15). LLC cells were washed twice with PBS and filtered through a $40 \mu \mathrm{m}$ filter membrane prior to being resuspended at a density of $2 \times 10^{7}$ cells $/ \mathrm{ml}$ and subcutaneously injected into the left forelimbs of these mice. Following 10 days, a total of 34 mice meeting the experimental requirements, that the tumor sizes were similar, were identified.

In the avasimibe treatment trial, 24 mice were randomized into 4 groups: A control group, a cyclophosphamide (CTX; $20 \mathrm{mg} / \mathrm{kg}$, once every other day) group, an avasimibe $(15 \mathrm{mg} / \mathrm{kg}$, once every 2 days) group and a CTX + avasimibe group. From days 10-35 following tumor inoculation, CTX or avasimibe were injected intraperitoneally and mouse body weight was monitored once weekly. On day 35, all mice were euthanized and tumors, livers, lungs and spleens were harvested. Spleens were then weighed, tumor volume was determined, and liver and lung samples were inspected for evidence of metastases.

For the remaining 10 tumor model mice, the lungs were collected on day 35 . In parallel, lung samples from 10 healthy tumor-free mice were also collected. Lung tissue protein was then extracted and ACAT-1 expression was detected by western blotting.

Statistical analysis. All in vitro experiments were conducted at least three times. SPSS v16.0 (SPSS, Inc., Chicago, IL, USA) was used for all statistical analyses. Data are provided as the mean \pm standard deviation, and were assessed using one-way analyses of variance and Student's t-tests. The least significant difference-t test was used as a post-hoc test for comparison between multiple groups. $\mathrm{P}<0.05$ was considered to indicate a statistically significant difference.

\section{Results}

Decreased expression levels of ACAT-1 inhibit LLC cell proliferation. LLC cells were treated with different avasimibe concentrations to inhibit ACAT-1, revealing a significant dose- and time-dependent suppression of proliferation as revealed using a CCK- 8 assay $(\mathrm{P}<0.05$; Fig. $1 \mathrm{~A}$ and $\mathrm{B})$. The cell viability rates in the blank group and the avasimibe $(2.5,5,10$ and $20 \mu \mathrm{M})$ groups were $100.00 \pm 0.00,63.57 \pm 4.88$, $45.47 \pm 5.35,37.66 \pm 3.72$ and $30.59 \pm 1.24 \%$, respectively (Fig. 1A). In addition, the viability of the control group and
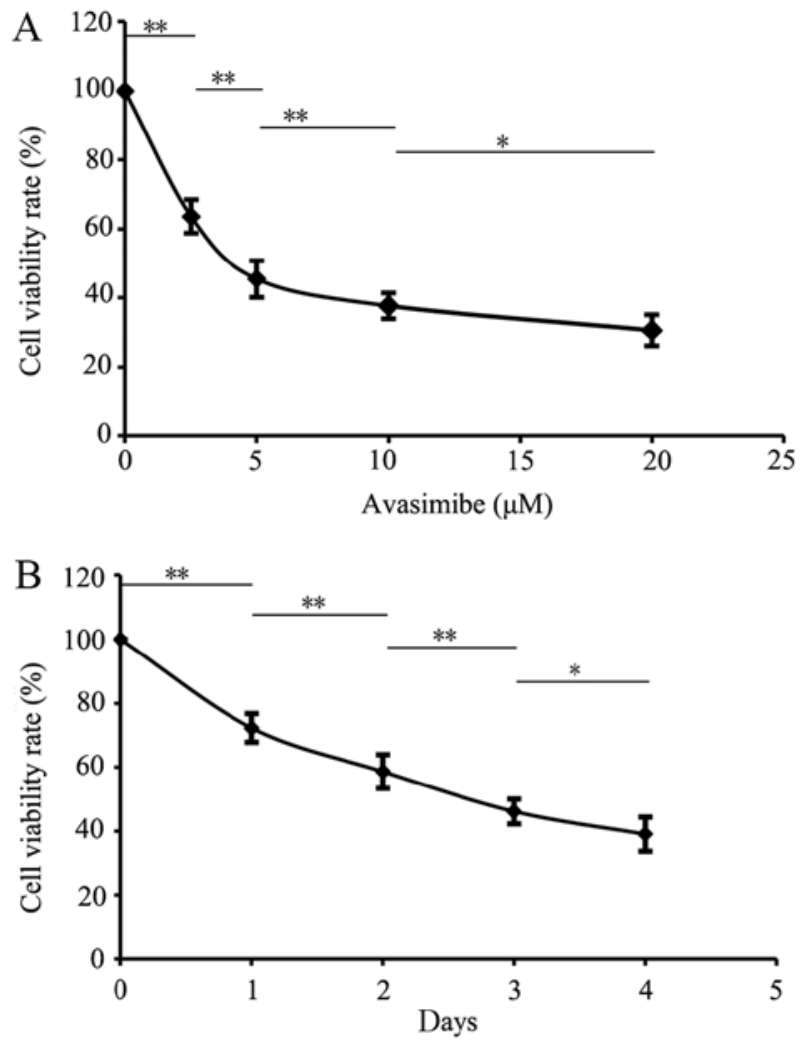

Figure 1. Downregulating ACAT-1 expression using avasimibe may inhibit the viability of LLC cells. (A) Effect of different concentrations of avasimibe $(0,2.5,5,10$ and $20 \mu \mathrm{M})$ on LLC cell viability at $72 \mathrm{~h}$, with $0 \mu \mathrm{M}$ avasimibe used as a control. (B) Effects of avasimibe $(10 \mu \mathrm{M})$ on the viability of LLC cells at $0,24,48,72$ and $96 \mathrm{~h}$, with $0 \mathrm{~h}$ used as a control. ${ }^{*} \mathrm{P}<0.05$ and ${ }^{* *} \mathrm{P}<0.01$ with comparisons shown by lines. ACAT-1, acetyl-CoA acetyltransferase 1; LLC, Lewis lung cancer.

the groups at $1,2,3$ and 4 days were $100.00 \pm 0.00,72.21 \pm 4.50$, $58.60 \pm 5.25,46.11 \pm 3.9$ and $39.02 \pm 3.04 \%$, respectively (Fig. 1B). These results therefore demonstrated that avasimbe inhibits LLC cell proliferation compared with the controls.

Decreased ACAT-1 expression inhibits LLC cell migration. As presented in Fig. 2, cell migration was significantly reduced in the avasimibe group compared with the control group $(\mathrm{P}<0.01)$. The wound-healing rates of the avasimibe-treated (5 and $10 \mu \mathrm{M}$ ) groups and the blank group were $18.90 \pm 2.37$, $11.07 \pm 1.27$ and $40.63 \pm 4.98 \%$, respectively. This indicated that avasimibe inhibited the migration of LLC cells compared with the controls.

Avasimibe downregulates ACAT-1 expression in LLC cells. LLC cells were treated with different avasimibe doses for $72 \mathrm{~h}$, following which the ability of avasimibe to inhibit ACAT-1 expression was validated using flow cytometry, western blotting and immunofluorescence microscopy. As presented in Fig. 3, it was revealed that avasimibe treatment resulted in the significant downregulation of ACAT-1 protein expression levels in LLC cells compared with the control groups $(\mathrm{P}<0.05)$.

Avasimibe promotes the apoptosis of LLC cells. Based on a flow cytometry-based analysis, avasimibe $(10 \mu \mathrm{M})$ 

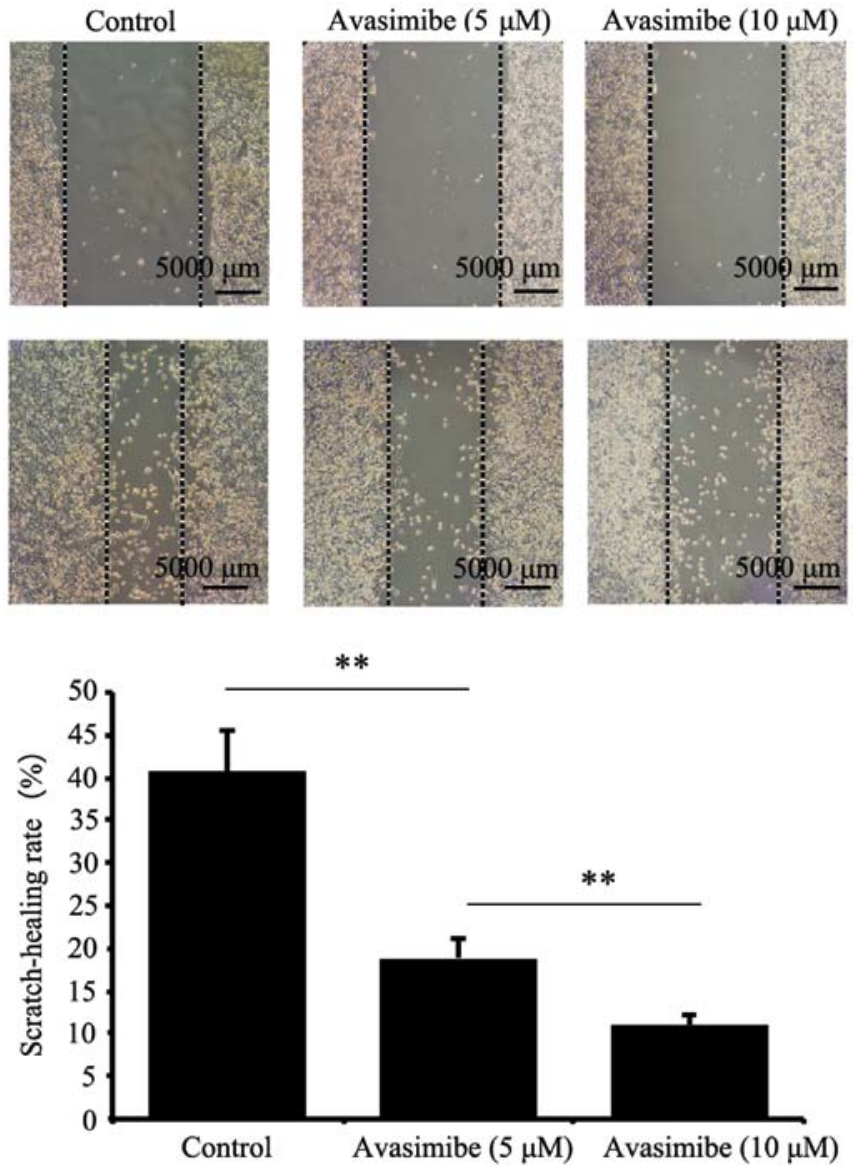

Figure 2. Downregulating acetyl-CoA acetyltransferase 1 expression using avasimibe may inhibit LLC cell migration. Scale bars $=5,000 \mu \mathrm{m}$. The effects of avasimibe ( 5 and $10 \mu \mathrm{M}$ ) on LLC cell migration ability at $48 \mathrm{~h}$ post-treatment, with $0 \mu \mathrm{M}$ avasimibe used as a control. ${ }^{* *} \mathrm{P}<0.01$ with comparisons shown by lines. LLC, Lewis lung cancer.

treatment of LLC cells for $72 \mathrm{~h}$ significantly increased the apoptotic rate of these cells compared with the control group $(\mathrm{P}<0.05$; Fig. 4).

Avasimibe inhibits LLC growth and metastasis in mice. In the present study, a subcutaneous mouse LLC model was established in order to validate the anti-tumor effects of ACAT-1 inhibition in vivo. The results revealed that avasimibe may significantly reduce tumor size $(\mathrm{P}<0.01$; Fig. $5 \mathrm{~A}$ and $\mathrm{B})$, and resulted in a significant increase in spleen weights and spleen indexes $(\mathrm{P}<0.01$; Fig. $5 \mathrm{~F}$ and $\mathrm{G})$ compared with the control groups. Compared with the CTX and avasimibe mono-treatment groups, the combination of CTX+avasimibe was able to significantly inhibit tumor growth more effectively than either single treatment $(\mathrm{P}<0.01$; Fig. 5B). Avasimibe treatment did not result in notable changes in mouse body weight over time (Fig. 5C). Metastatic lesions in distant organs (liver and lung) were also assessed at the study endpoint, with at least one metastatic lesion being observed in the liver and lung of each control mouse, compared with the lack of evidence of metastatic lesions in other groups (Fig. 5D and E). These results further confirmed that avasimibe inhibited tumor growth and enhanced immune responses in mice with LLC tumor types. Furthermore, avasimibe enhanced the anti-tumor effects of CTX.
Expression of ACAT-1 in the tumor model mice is higher compared with in the control mice. As presented in Fig. 6, the expression levels of ACAT-1 in LLC mice were significantly higher compared with that in the control mice $(\mathrm{P}<0.05)$.

\section{Discussion}

In the present study, an association between ACAT-1 and lung cancer growth and metastasis was identified. ACAT-1 has primarily been studied in the context of cardiovascular diseases, with numerous ACAT inhibitors having been developed to treat diseases including cardiovascular diseases and Alzheimer's disease (16,17). Recently, researchers have determined that ACAT-1 expression and activity are upregulated in numerous tumor cells, and ACAT-1 inhibitors exhibit anti-tumor activity in certain experimental models in vivo and in vitro $(9,18-22)$, including in renal cell carcinoma, colon cancer, breast cancer, glioma, pancreatic ductal adenocarcinoma, chronic myelogenous leukemia and lung cancer. A previous paper studied the function of ACAT-1 in lung cancer cells, uncovering results which differed from those of the present study (19). This may be due to a number of reasons; firstly, this may be that this previous study did not perform migration experiments to investigate the effect of avasimibe on lung cancer cell migration. Secondly, this previous study used A549 cells, which are distinct from LLC cells. Thirdly, this previous study did not conduct animal model experiments assessing lung cancer. Finally, this previous study investigated the anti-tumor effects of avasimbe by detecting cholesterol in cells, whereas the present study focused specifically on the expression of ACAT-1. Here, it was demonstrated that the inhibition of ACAT-1 may be effective in treating lung cancer.

The present study provides novel insights into the importance of ACAT-1 in LLC cells, suggesting that this protein serves an important function in the growth and metastasis of LLC cells and the development of LLC in mice. Targeting ACAT-1 is thus a potential novel therapeutic strategy for treating lung cancer. By treating LLC cells with avasimibe, an ACAT-1 inhibitor, it was revealed that avasimibe reduced the expression of ACAT-1 and significantly inhibited LLC cell proliferation and migration compared with the control cells $(\mathrm{P}<0.05)$, further promoting the apoptosis of these LLC cells. The present study additionally established a mouse model of LLC to verify the anti-tumor effects of ACAT-1 inhibitors in vivo. Mice were treated with saline, CTX (20 mg/kg), avasimibe $(15 \mathrm{mg} / \mathrm{kg}$ ) or CTX+avasimibe. It was revealed that avasimibe did not cause weight loss in mice. No evidence of avasimibe toxicity in mice was observed, and avasimibe alone or in combination with the existing chemotherapy CTX was sufficient to inhibit tumor growth and metastasis, with avasimibe further increasing tumor sensitivity to CTX. Studies have reported that avasimibe may enhance the efficacy of gemcitabine as a means of combatting pancreatic ductal adenocarcinoma proliferation (22), and may additionally enhance the efficacy of imatinib as a means of disrupting the growth of chronic myelogenous leukemia (9). The present study further observed that the inhibition of ACAT-1 enhanced immune responses in mice, as evidenced 


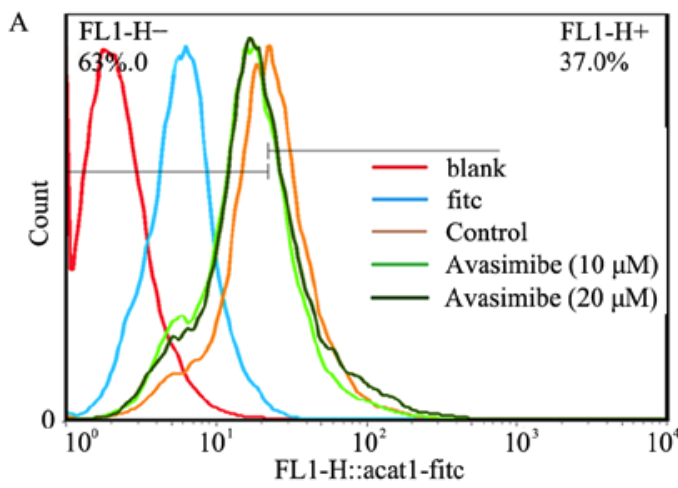

B

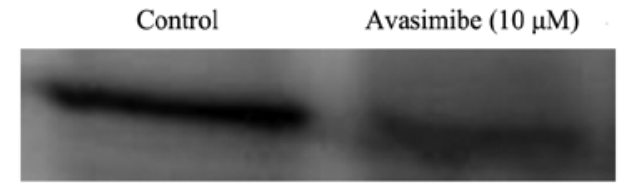

ACAT-1

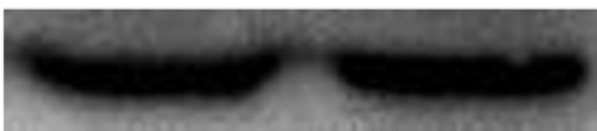

$\beta$-actin
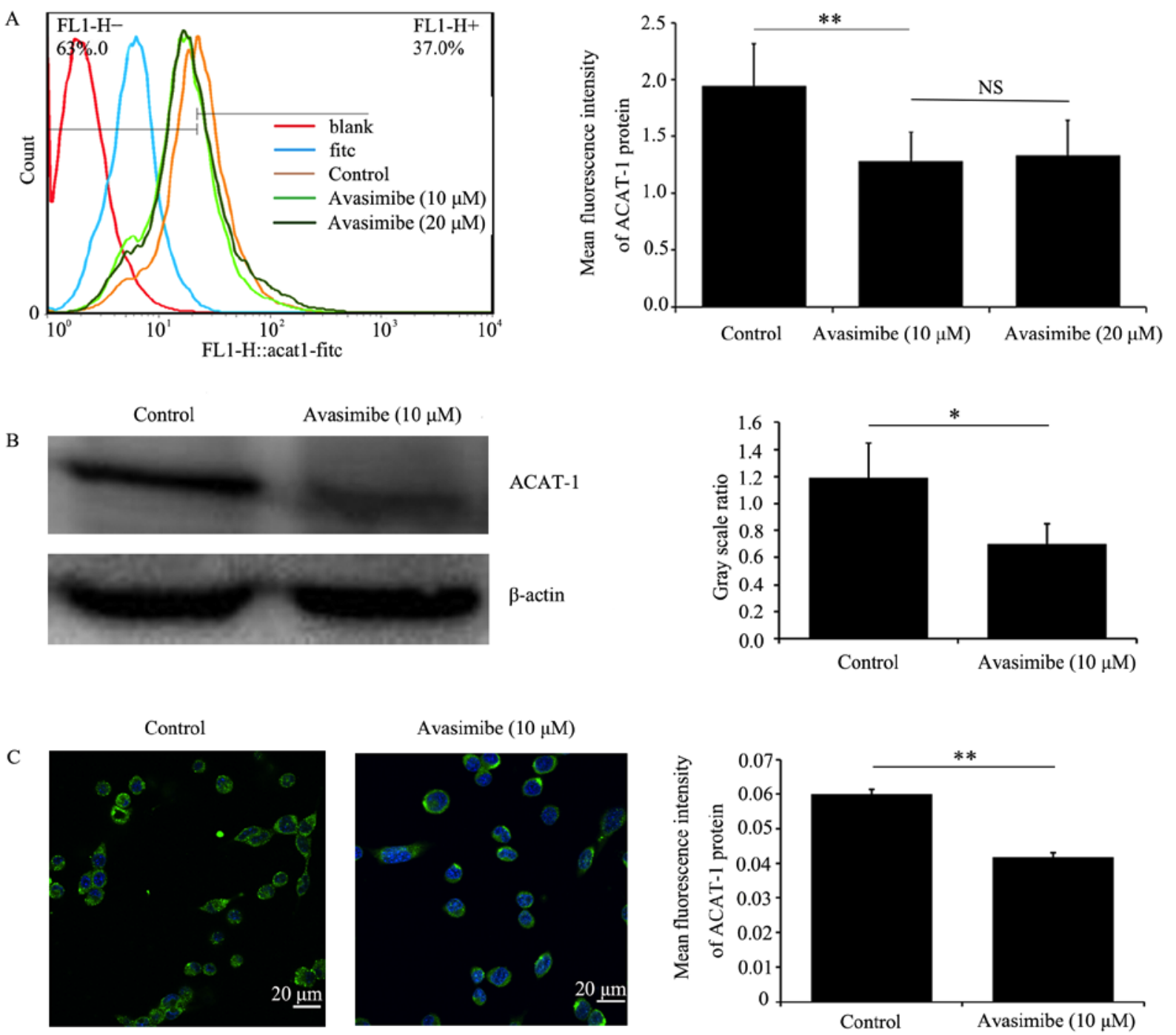

Figure 3. Avasimibe regulates the expression levels of ACAT-1 in LLC cells. (A) ACAT-1 protein levels were quantified by flow cytometry. The effect of avasimibe $(10$ and $20 \mu \mathrm{M})$ on the expression levels of ACAT-1 in LLC cells subsequent to treatment for $72 \mathrm{~h}$ was determined, with $0 \mu \mathrm{M}$ used as a control. (B) ACAT-1 protein levels in LLC cells were quantified by western blotting (normalized to $\beta$-actin) in order to assess the effects of treatment with $10 \mu \mathrm{M}$ avasimibe for $72 \mathrm{~h}$, with $0 \mu \mathrm{M}$ used as a control. (C) ACAT-1 protein levels were quantified by immunofluorescence microscopy following $72 \mathrm{~h}$ treatment with $10 \mu \mathrm{M}$ avasimibe, with $0 \mu \mathrm{M}$ used as a control. Scale bars $=20 \mu \mathrm{m}$. ${ }^{*} \mathrm{P}<0.05$ and ${ }^{* *} \mathrm{P}<0.01$ with comparisons shown by lines. ACAT- 1 , acetyl-CoA acetyltransferase 1; LLC, Lewis lung cancer; FITC, fluorescein isothiocyanate; NS, not significant.

by measuring the spleen weight and spleen indexes of treated mice. Additionally, it was revealed that the expression of ACAT-1 in the lung tissue of the LLC mice was higher compared with in healthy mice. These results will provide the basis for further biological research to fully understand the function of ACAT-1 in the occurrence and development of cancer.

The mechanisms linking ACAT-1 to lung cancer growth and metastasis require further study. One potential link is the fact that ACAT-1 may reduce the levels of the pyruvate dehydrogenase complex (PDC) (23). As early as the 1950s, German scientists proposed the Warburg effect (24); unlike the oxidative metabolism of normal cells, tumor cells undergo extensive aerobic glycolysis to provide the energy necessary for growth in an oxygen-rich environment. PDC is extremely important mediator of the interface between glycolysis and oxidative phosphorylation (25). Studies have demonstrated that decreased PDC levels are able to enhance glycolysis in tumor cells, thus providing a metabolic advantage for tumor growth (26-28). ACAT-1 is an upstream regulator of pyruvate dehydrogenase and pyruvate dehydrogenase phosphatase (PDP), which acetylates pyruvate dehydrogenase E1-a subunit and PDP-1 to downregulate PDC levels (23). In the present study, the expression of ACAT-1 was successfully inhibited using avasimibe, which in theory may increase PDC levels and thereby inhibit tumor growth.

In addition to promoting glycolysis, ACAT-1 serves a key role in cholesterol metabolism, catalyzing free cholesterol conversion into cholesterol esters (29). ACAT-1 may increase cholesterol ester levels and elevate blood sugar in the body, resulting in insulin secretion which may in turn increase the activity of insulin-like growth factor (IGF). Increased IGF function may promote cell mitosis, thereby accelerating cell proliferation and promoting tumor growth (30-32). Studies have demonstrated that IGF is closely associated with lung cancer progression $(33,34)$. Thus, the inhibition of ACAT-1 

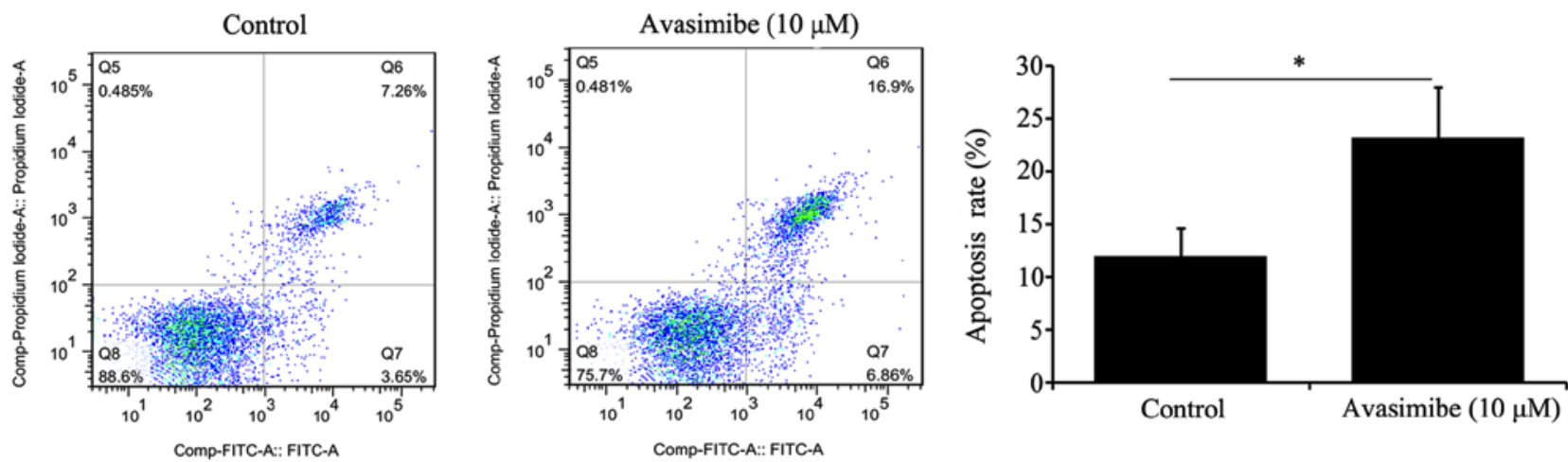

Figure 4. Effect of $72 \mathrm{~h}$ treatment with $10 \mu \mathrm{M}$ avasimibe on the apoptotic rate of Lewis lung cancer cells, with $0 \mu \mathrm{M}$ used as a control. "P<0.05 with comparisons shown by lines. FITC, fluorescein isothiocyanate.
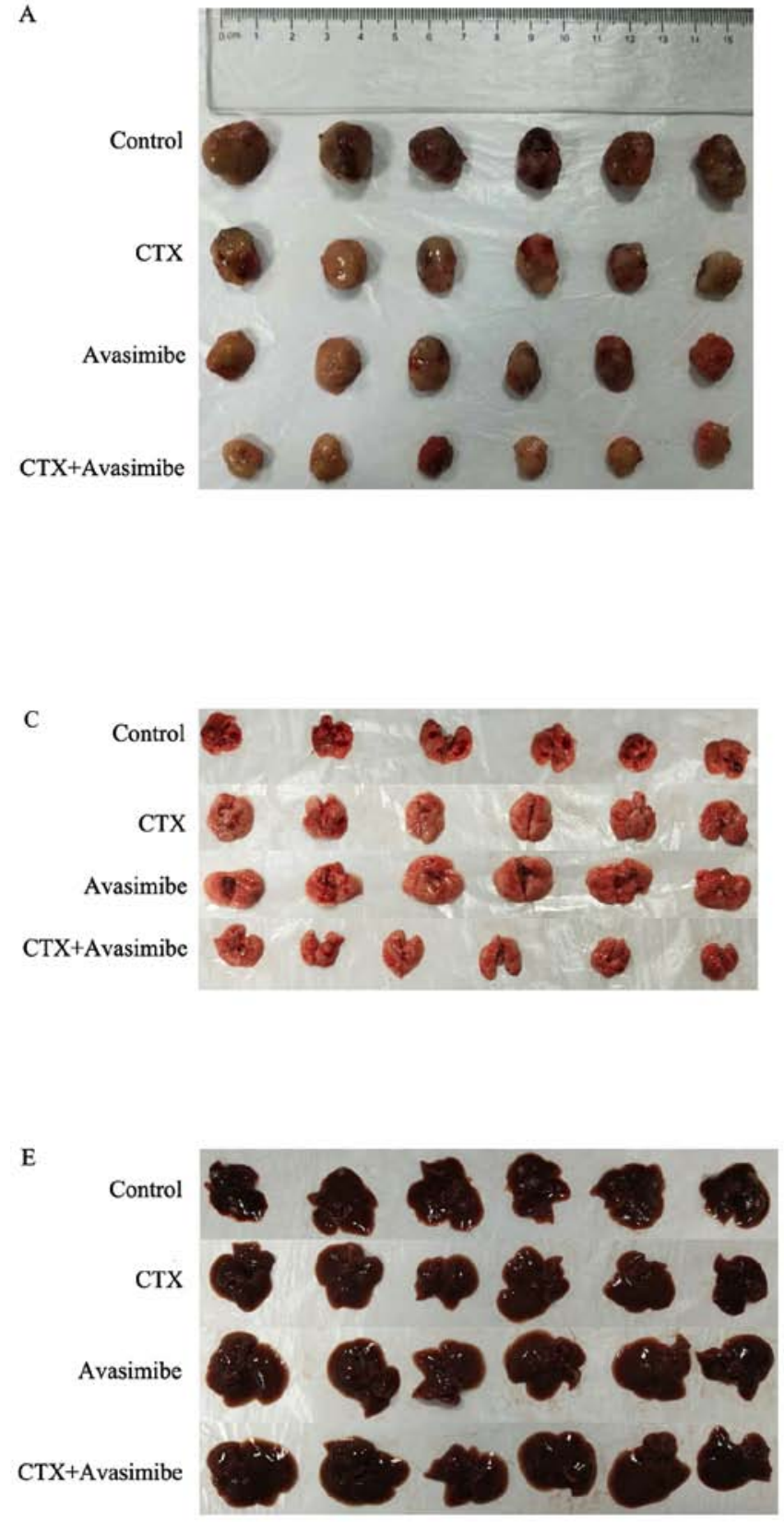
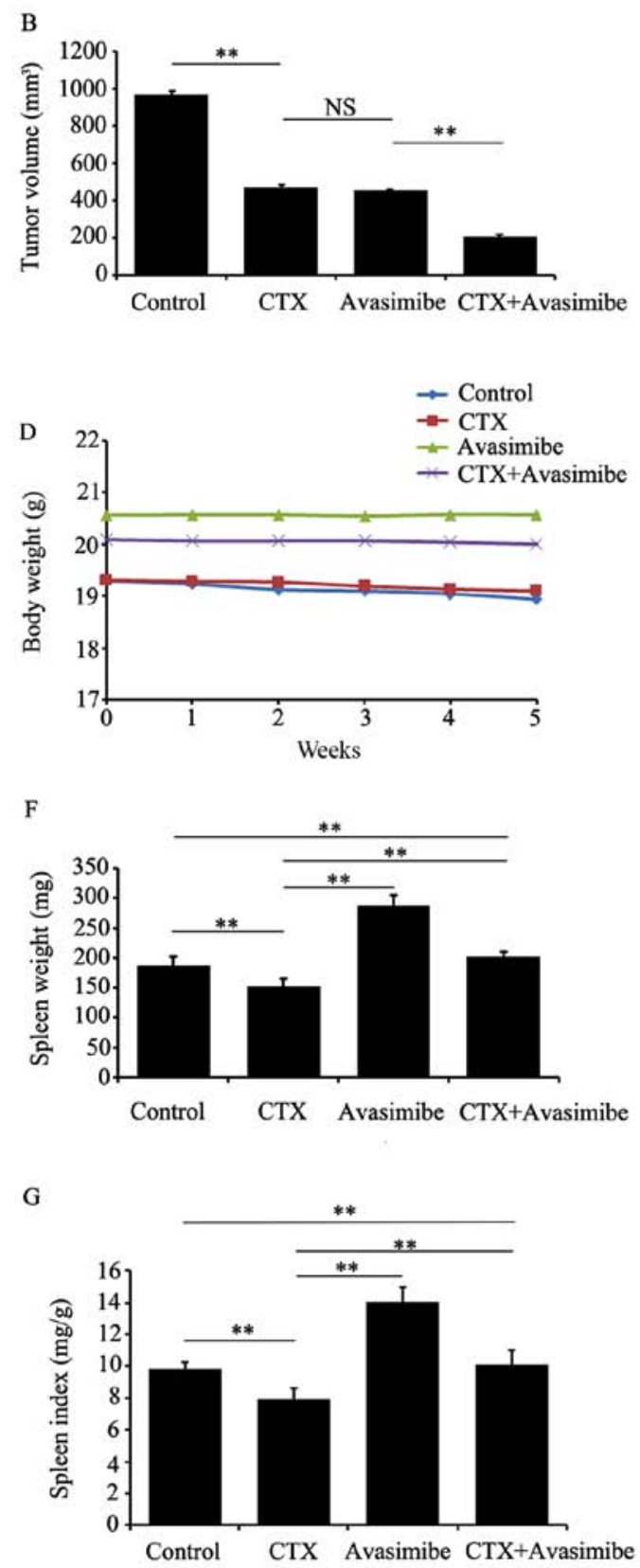

Figure 5. Therapeutic effect of avasimibe in a mouse model of Lewis lung carcinoma. (A) Images of the tumor; (B) ex vivo measurements of the tumor size; (C) monitoring of the mouse body weight over time (0-5 weeks); (D) Images of metastatic lesions of the lung; (E) ex vivo measurements of spleen weights; (F) Images of metastatic lesions of the liver; (G) ex vivo measurements of spleen indexes. ${ }^{* *} \mathrm{P}<0.01$ with comparisons shown by lines. CTX, cyclophosphamide. 

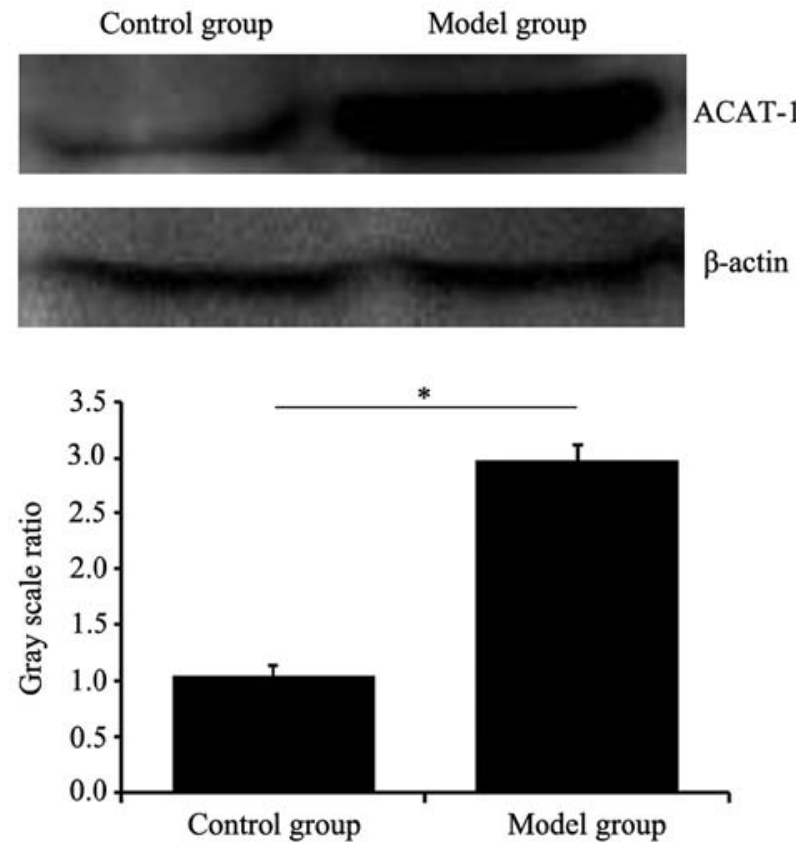

Figure 6. Differences in ACAT-1 expression levels between control mice and tumor model mice. ${ }^{*} \mathrm{P}<0.05$ with comparisons shown by lines. ACAT-1, acetyl-CoA acetyltransferase 1 .

expression reduces cholesterol ester levels, and may thereby result in decreased IGF activity, resulting in the inactivation of phosphoinositide 3 kinase/protein kinase B or RAS type GTPase family/mitogen-activated protein kinase signaling pathways, thereby inhibiting tumor growth and metastasis (35).

Recent studies (36-38) have also identified an association between ACAT-1 and the immune system, as inhibiting ACAT-1 expression may enhance the anti-tumor activity of cluster of differentiation (CD) $8^{+} \mathrm{T}$ cells. During $\mathrm{T}$ cell activation, lipid metabolism is required for membrane biosynthesis and cell growth. Cholesterol regulates membrane protein function, participates in membrane trafficking and regulates transmembrane signaling $(39,40)$. Previous studies have also reported that ACAT-1 inhibitors potentiate the anti-tumor effects of human chimeric antigen receptor-modified $\mathrm{T}$ cells, and that $\mathrm{CD}^{+} \mathrm{T}$ cell responses to melanoma may be enhanced by inhibiting cholesterol esterification in mice via ACAT-1 inhibition $(41,42)$. The present study similarly observed that avasimibe may improve immune responses in tumor-bearing mice, which may additionally be associated with ACAT-1 affecting immune system function. The avasimibe and CTX+avasimibe group exhibited increased spleen weights and spleen index values compared with the control group, but these values were higher in the avasimibe treatment group compared with the CTX+avasimibe group, which may be due to the effects of CTX on the immune system in these mice. CTX is commonly used as an immunosuppressant to inhibit tumor growth, which may inhibit immune system function (43-45). Furthermore, the inhibition of ACAT-1 by avasimibe may improve the immune function in mice $(38,41,42)$. Therefore, the regulation of cholesterol metabolism may have a profound impact on anti-tumor responses through these other signaling pathways. Further research will therefore be required to fully elucidate the underlying molecular mechanisms.

The safety and toxicity of avasimibe and CTX have been evaluated in clinical trials. In prior clinical trials for the treatment of atherosclerosis, avasimibe proved to have good safety in humans $(46,47)$. CTX is a commonly used chemotherapeutic drug, and its clinical safety has also been confirmed (48-50). At present, to the best of our knowledge there has been no clinical trial assessing the combination of avasimibe and CTX. It is therefore necessary to conduct clinical trials to confirm the effectiveness and safety of this combination.

In summary, a preliminary conclusion may be drawn from the present study; that inhibiting the expression of ACAT-1 may weaken the proliferation and metastasis of LLC cells. Avasimibe may not only inhibit the tumor growth and development of distant metastases in mice, but may additionally enhance the anti-tumor efficacy of chemotherapeutic drug treatment and enhance immune responses in vivo. Therefore, targeted blocking of the ACAT-1 metabolism pathway has potential for use as a novel treatment strategy for lung cancer that may be combined with chemotherapy to provide novel treatment strategies for this disease. This treatment has the potential to delay the progression and metastasis of cancer, thereby prolonging patient survival time and improving quality of life. However, the further study of ACAT-1 is still required in order to fully understand the function of ACAT-1 in the development and progression of lung cancer.

\section{Acknowledgements}

Not applicable.

\section{Funding}

The present study was supported by the Medical ResearchProject of Anhui Provincial Department of Health (grant no. 09C171), the key project of Anhui Provincial University Natural Science Research Project (grant no. KJ2016A483) and grants from the National Natural Science Foundation of China (grant no. 21707002) and the Graduate School of Innovation (grant no. Byycxz1722).

\section{Availability of data and materials}

All data generated or analyzed during this study are included in this published article.

\section{Authors' contributions}

MB designed the study, contributed to the conception of the study and the analysis and intepretation of the experimental data, revised the manuscript, and gave final approval of the version to be published. XuxQ, WL, YL and SZ performed the experiments. HaoZ, ZG, HW and JH performed the data analysis. HaiZ, MS, YW, JY, XujQ and ZZ participated in developing the animal model. All authors read and approved the manuscript and agreed to be accountable for all aspects of the research in ensuring that the accuracy or integrity of any part of the work are appropriately investigated and resolved. 


\section{Ethics approval and consent to participate}

All experiments were performed in accordance with a protocol ethically approved by the Institutional Animal Care and Use Committee of Bengbu Medical College (Bengbu, China).

\section{Patient consent for publication}

Not applicable.

\section{Competing interests}

The authors declare that they have no competing interests.

\section{References}

1. Siegel RL, Miller KD and Jemal A: Cancer statistics, 2018. CA Cancer J Clin 68: 7-30, 2018

2. Chen W, Zheng R, Zhang S, Zeng H, Zuo T, Xia C, Yang Z and He J: Cancer incidence and mortality in China in 2013: An analysis based on urbanization level. Chin J Cancer Res 29: 1-10, 2017.

3. Zhang C, Leighl NB, Wu YL and Zhong WZ: Emerging therapies for non-small cell lung cancer. J Hematol Oncol 12: 45, 2019.

4. Wu SG and Shih JY: Management of acquired resistance to EGFR TKI-targeted therapy in advanced non-small cell lung cancer. Mol Cancer 17: 38, 2018.

5. Solomon BJ, Besse B, Bauer TM, Felip E, Soo RA, Camidge DR, Chiari R, Bearz A, Lin CC, Gadgeel SM, et al: Lorlatinib in patients with ALK-positive non-small-cell lung cancer: Results from a global phase 2 study. Lancet Oncol 19: 1654-1667, 2018.

6. Zhu Y, Chen CY, Li J, Cheng JX, Jang M and Kim KH: In vitro exploration of ACAT contributions to lipid droplet formation during adipogenesis. J Lipid Res 59: 820-829, 2018.

7. Allott EH, Masko EM, Freedland AR, Macias E, Pelton K, Solomon KR, Mostaghel EA, Thomas GV, Pizzo SV Freeman MR, et al: Serum cholesterol levels and tumor growth in a PTEN-null transgenic mouse model of prostate cancer. Prostate Cancer Prostatic Dis 21: 196-203, 2018.

8. Li J, Gu D, Lee SS, Song B, Bandyopadhyay S, Chen S, Konieczny SF, Ratliff TL, Liu X, Xie J, et al: Abrogating cholesterol esterification suppresses growth and metastasis of pancreatic cancer. Oncogene 35: 6378-6388, 2016.

9. Bandyopadhyay S, Li J, Traer E, Tyner JW, Zhou A, Oh ST and Cheng JX: Cholesterol esterification inhibition and imatinib treatment synergistically inhibit growth of BCR-ABL mutation-independent resistant chronic myelogenous leukemia. PLoS One 12: e0179558, 2017.

10. Ohmoto T,Nishitsuji K, YoshitaniN, Mizuguchi M, Yanagisawa Y, Saito H and Sakashita N: K604, a specific acyl-CoA:cholesterol acyltransferase 1 inhibitor, suppresses proliferation of U251-MG glioblastoma cells. Mol Med Rep 12: 6037-6042, 2015.

11. de Gonzalo-Calvo D, López-Vilaró L, Nasarre L, Perez-Olabarria M, Vázquez T, Escuin D, Badimon L, Barnadas A, Lerma E and Llorente-Cortés V: Intratumor cholesteryl ester accumulation is associated with human breast cancer proliferation and aggressive potential: A molecular and clinicopathological study. BMC Cancer 15: 460, 2015.

12. Zhang L, Kim SB, Luitel K and Shay JW: Cholesterol depletion by TASIN-1 induces apoptotic cell death through the ER stress/ROS/JNK signaling in colon cancer cells. Mol Cancer Ther 17: 943-951, 2018.

13. Zhao H, Wu M, Zhu L, Tian Y, Wu M, Li Y, Deng L, Jiang W, Shen W, Wang Z, et al: Cell-penetrating peptide-modified targeted drug-loaded phase-transformation lipid nanoparticles combined with low-intensity focused ultrasound for precision theranostics against hepatocellular carcinoma. Theranostics 8 : 1892-1910, 2018.

14. Hu Y, Rao SS, Wang ZX, Cao J, Tan YJ, Luo J, Li HM, Zhang WS, Chen CY and Xie H: Exosomes from human umbilical cord blood accelerate cutaneous wound healing through miR-21-3p-mediated promotion of angiogenesis and fibroblast function. Theranostics 8: 169-184, 2018.
15. Stephenson W: Deficiencies in the National Institute of Health's guidelines for the care and protection of laboratory animals. J Med Philos 18: 375-388, 1993.

16. Zanoni P, Khetarpal SA, Larach DB, Hancock-Cerutti WF, Millar JS, Cuchel M, DerOhannessian S, Kontush A, Surendran P, Saleheen D, et al: Rare variant in scavenger receptor BI raises HDL cholesterol and increases risk of coronary heart disease. Science 351: 1166-1171, 2016

17. Chang TY, Yamauchi Y, Hasan MT and Chang C: Cellular cholesterol homeostasis in Alzheimer's disease. J Lipid Res 58: 2239-2254, 2017.

18. Zhao Z, Wu F, Ding S, Sun L, Liu Z, Ding K and Lu J: Label-free quantitative proteomic analysis reveals potential biomarkers and pathways in renal cell carcinoma. Tumour Biol 36: 939-951, 2015.

19. Lee SS, Li J, Tai JN, Ratliff TL, Park K and Cheng JX: Avasimibe encapsulated in human serum albumin blocks cholesterol esterification for selective cancer treatment. ACS Nano 9: 2420-2432, 2015.

20. Antalis CJ, Uchida A, Buhman KK and Siddiqui RA: Migration of MDA-MB-231 breast cancer cells depends on the availability of exogenous lipids and cholesterol esterification. Clin Exp Metastasis 28: 733-741, 2011.

21. Bemlih S, Poirier MD and Andaloussi AE: Acyl-coenzyme A: cholesterol acyltransferase inhibitor Avasimibe affect survival and proliferation of glioma tumor cell lines. Cancer Biol Ther 9: 1025-1032, 2010

22. Li J, Qu X, Tian J, Zhang JT and Cheng JX: Cholesterol esterification inhibition and gemcitabine synergistically suppress pancreatic ductal adenocarcinoma proliferation. PLoS One 13: e0193318, 2018.

23. Fan J, Shan C, Kang HB, Elf S, Xie J, Tucker M, Gu TL, Aguiar M, Lonning S, Chen H, et al: Tyr phosphorylation of PDP1 toggles recruitment between ACAT1 and SIRT3 to regulate the pyruvate dehydrogenase complex. Mol Cell 53: 534-548, 2014.

24. Warburg O: On the origin of cancer cells. Science 123: 309-314, 1956.

25. Harris RA, Bowker-Kinley MM, Huang B and Wu P: Regulation of the activity of the pyruvate dehydrogenase complex. Advan Enzyme Regul 42: 249-259, 2002.

26. Zhao H, Jiang H, Li Z, Zhuang Y, Liu Y, Zhou S, Xiao Y, Xie C, Zhou $\mathrm{F}$ and Zhou Y: 2-Methoxyestradiol enhances radiosensitivity in radioresistant melanoma MDA-MB-435R cells by regulating glycolysis via HIF-1 $\alpha / \mathrm{PDK} 1$ axis. Int $\mathrm{J}$ Oncol 50: 1531-1540, 2017

27. Hitosugi T, Fan J, Chung TW, Lythgoe K, Wang X, Xie J, Ge Q, Gu T, Polakiewicz RD, Roesel JL, et al: Tyrosine phosphorylation of mitochondrial pyruvate dehydrogenase kinase 1 is important for cancer metabolism. Mol Cell 44: 864-877, 2011.

28. Lin R, Elf S, Shan C, Kang HB, Ji Q, Zhou L, Hitosugi T, Zhang L, Zhang S, Seo JH, et al: 6-Phosphogluconate dehydrogenase links oxidative PPP, lipogenesis and tumour growth by inhibiting LKB1-AMPK signalling. Nat Cell Biol 17: 1484-1496, 2015.

29. Buhman KF, Accad $M$ and Farese RV: Mammalian acyl-CoA:cholesterol acyltransferases. Biochim Biophys Acta 1529: 142-154, 2000.

30. Behjati S, Tarpey PS, Haase K, Ye H, Young MD, Alexandrov LB, Farndon SJ, Collord G, Wedge DC, Martincorena I, et al: Recurrent mutation of IGF signalling genes and distinct patterns of genomic rearrangement in osteosarcoma. Nat Commun 8: 15936, 2017.

31. Obr AE, Kumar S, Chang YJ, Bulatowicz JJ, Barnes BJ, Birge RB, Lazzarino DA, Gallagher E, LeRoith D and Wood TL: Insulin-like growth factor receptor signaling in breast tumor epithelium protects cells from endoplasmic reticulum stress and regulates the tumor microenvironment. Breast Cancer Res 20 $138,2018$.

32. Cao HY, Guo XF, Zhu XF, Li SS and Zhen YS: A ligand-based and enediyne-energized bispecific fusion protein targeting epidermal growth factor receptor and insulin-like grow th factor- 1 receptor shows potent antitumor efficacy against esophageal cancer. Oncol Rep 37: 3329-3340, 2017.

33. Mano SS, Uto K and Ebara M: Material-induced Senescence (MIS): Fluidity induces senescent type cell death of lung cancer cells via insulin-like growth factor binding protein 5 . Theranostics 7: 4658-4670, 2017.

34. Mochizuki S, Shimoda M, Abe H, Miyamae Y, Kuramoto J, Aramaki-Hattori N, Ishii K, Ueno H, Miyakoshi A, Kojoh K, et al: Selective inhibition of ADAM28 suppresses lung carcinoma cell growth and metastasis. Mol Cancer Ther 17: 2427-2438, 2018 . 
35. Wang H, Su X, Fang J, Xin X, Zhao X, Gaur U, Wen Q, Xu J, Little PJ and Zheng W: Tanshinone IIA attenuates insulin like growth factor 1-induced cell proliferation in PC12 cells through the PI3K/Akt and MEK/ERK pathways. Int J Mol Sci 19: pii: E2719, 2018.

36. Chen X, Song Q, Xia L and Xu X: Synergy of dendritic cell vaccines and avasimibe in treatment of head and neck cancer in mice. Med Sci Monith 23: 4471-4476, 2017.

37. Bernard NJ: Cholesterol test for T cells. Nat Rev Rheumatol 15: $189,2019$.

38. Li M, Yang Y, Wei J, Cun X, Lu Z, Qiu Y, Zhang Z and He Q: Enhanced chemo-immunotherapy against melanoma by inhibition of cholesterol esterification in $\mathrm{CD}^{+} \mathrm{T}$ cells Nanomedicine 14: 2541-2550, 2018.

39. Kidani Y, Elsaesser H, Hock MB, Vergnes L, Williams KJ, Argus JP, Marbois BN, Komisopoulou E, Wilson EB, Osborne TF, et al: Sterol regulatory element-binding proteins are essential for the metabolic programming of effector T cells and adaptive immunity. Nat Immunol 14: 489-499, 2013

40. Molnár E, Swamy M, Holzer M, Beck-García K, Worch R, Thiele C, Guigas G, Boye K, Luescher IF, Schwille P, et al: Cholesterol and sphingomyelin drive ligand-independent T-cell antigen receptor nanoclustering. J Biol Chem 287: 42664-42674, 2012 .

41. Zhao L, Li J, Liu Y, Kang L, Chen H, Jin Y, Zhao F, Feng J, Fang C, Zhu B, et al: Cholesterol esterification enzyme inhibition enhances antitumor effects of human chimeric antigen receptors modified T cells. J Immunother 41: 45-52, 2018.

42. Yang W, Bai Y, Xiong Y, Zhang J, Chen S, Zheng X, Meng X, Li L, Wang J, Xu C, et al: Potentiating the antitumour response of CD8(+) T cells by modulating cholesterol metabolism. Nature 531: 651-655, 2016.

43. Wang $\mathrm{H}$, Yang $\mathrm{S}$, Wang $\mathrm{Y}$, Jiang $\mathrm{T}$, Li $\mathrm{S}$ and $\mathrm{Lv} \mathrm{Z}$ Immunoenhancement effects of glycosaminoglycan from Apostichopus japonicus: In vitro and in cyclophosphamide-induced immunosuppressed mice studies. Mar Drugs 15: pii: E347, 2017.
44. Zhu G, Jiang Y, Yao Y, Wu N, Luo J, Hu M, Tu Y and Xu M: Ovotransferrin ameliorates the dysbiosis of immunomodulatory function and intestinal microbiota induced by cyclophosphamide. Food Funct 10: 1109-1122, 2019.

45. Cheng D, Wan Z, Zhang X, Li J, Li H and Wang C: Dietary chlorella vulgaris ameliorates altered immunomodulatory functions in cyclophosphamide-induced immunosuppressive mice. Nutrients 9: pii: E708, 2017.

46. Chang TY, Li BL, Chang CC and Urano Y: Acyl-coenzyme A: Cholesterol acyltransferases. Am J Physiol Endocrinol Metab 297: E1-E9, 2009.

47. Pal P, Gandhi H, Giridhar R and Yadav MR: ACAT inhibitors: The search for novel cholesterol lowering agents. Mini Rev Med Chem 13: 1195-1219, 2013.

48. Sistigu A, Viaud S, Chaput N, Bracci L, Proietti E and Zitvogel L: Immunomodulatory effects of cyclophosphamide and implementations for vaccine design. Semin Immunopathol 33: 369-383, 2011.

49. Ganz PA, Romond EH, Cecchini RS, Rastogi P, Geyer CE Jr, Swain SM, Jeong JH, Fehrenbacher L, Gross HM, Brufsky AM, et al: Long-Term Follow-up of cardiac function and quality of life for patients in NSABP protocol B-31/NRG oncology: A randomized trial comparing the safety and efficacy of doxorubicin and cyclophosphamide (AC) followed by paclitaxel with ac followed by paclitaxel and trastuzumab in patients with node-positive breast cancer with tumors overexpressing human epidermal growth factor receptor 2. J Clin Oncol 35: 3942-3948, 2017

50. Garderet L, Kuhnowski F, Berge B, Roussel M, Escoffre-Barbe M, Lafon I, Facon T, Leleu X, Karlin L,Perrot A, et al: Pomalidomide, cyclophosphamide, and dexamethasone for relapsed multiple myeloma. Blood 132: 2555-2563, 2018.

This work is licensed under a Creative Commons Attribution-NonCommercial-NoDerivatives 4.0 International (CC BY-NC-ND 4.0) License. 